\title{
EDUCATION AND BEHAVIOURAL FAILURES
}

\author{
Venelin Terziev $^{\mathbf{}}$, Dimitar Kanev ${ }^{2}$ \\ ${ }^{1}$ Corresponding Member of the Russian Academy of Natural History, Moscow, Professor, Ph.D., \\ D.Sc. (National Security), D.Sc. (Ec.), University of Rousse, Rousse, Bulgaria; National Military \\ University, Veliko Tarnovo, Bulgaria; University of Telecommunications and Post, Sofia, Bulgaria, \\ terziev@skmat.com \\ ${ }^{2}$ Professor, Ph.D., D.Sc. (Ec.), Naval Academy, Varna, Bulgaria, kanev@dkanev.com \\ ${ }^{*}$ Corresponding author
}

\begin{abstract}
The work defences the thesis that even ensured equal opportunities to invest in education and to get better life, even if this is the best life alternative for them, young people and their families would hardly take complete advantage of these opportunities. This particularly regards the ones in an unequal position. The reasons are looked for in behavioural failures connected to hyperbolic discounting and to focusing on the present, momentum, stereotypes, herd-instinct behaviour, the paralysis at the availability of numerous options and defects of will. The work also suggests solutions, which to help young people and their families to take adequate advantage of educational opportunities and to develop their potential, getting over or softening behavioural deformations and deviations from reality.
\end{abstract}

Keywords: education, limited rationality, lack of foresight, momentum, herd-instinct behaviour

\section{INTRODUCTION}

Target of the present work is education, and subject - behavioural failures in education decisions. What we make our aim is to study the behavioural deformations impact upon the effectiveness of individual decisions for education. We use the behavioural economy's theoretical approach and verify the thesis that together with ensuring access to quality education, young people and their families are to be helped to take adequate advantage of that access, particularly those occupying low social-economic status.

\section{STATEMENT}

Education is major channel for accumulation of human capital and could be defined as set of skills, competencies and other characteristics that enhance labour productivity. (World Economic Forum, 2016) This turns it into critical factor for labour realisation and wealth of the particular individuals as well as for the economic progress and labour resources effective use within society. Many studies prove education is the major momentum of economic growth, employment and earnings. (Grant, 2017) Ignoring it would threaten the prosperity of future generations and would have many negative consequences for poverty, social security systems' sustainability, social exclusion and inequality. (Woessmann, 2015) 
High education leads to better realization on the labour market. The average unemployment in the Organization for Economic Co-operation and Development (OECD) countries among individuals of age of 25-64 years without secondary education is $12,4 \%$, and among the ones with secondary education is $7,3 \%$, and among the ones having higher education is $4,9 \%$. The ones participating in the labour force without secondary education are $56 \%$, the ones with secondary education $-74 \%$, the ones having bachelor degree $-82 \%$, the ones with master degree $-87 \%$, and the ones occupying doctor's or equivalent degree $-91 \%$. (OECD, 2016, pp. 90-94) Education is also a significant factor for forming income: the averaged data for the OECD countries shows that the income difference between the people having primary and secondary education is smaller than the one between people having secondary and higher education: individuals with lower than secondary education have 19\% lower income than the individuals with secondary education, while individuals with higher education have $55 \%$ higher income. More, individuals with master or doctor's degree have double income compared to the ones having secondary education, and individuals with bachelor degree get $48 \%$ more. An additional positive effect for higher education is that their income increases in the course of time, while the income of individuals with lower education are not only lower at the beginning of the labour realization but also decrease in the course of time (OECD, 2016, pp. 114-118)

The expenditures for education are high. The average direct private expenditures for getting secondary education in the OECD countries are 2500 dollars, and for getting higher education - 10500 dollars. The second component of expenditures for higher education has a higher value - the missed benefits that, in the OECD countries, vary from 18000 dollars in Poland to 90000 dollars in the Netherlands. (OECD, 2016, pp. 134-136) Despite high expenditures, education is a valuable investment and ensures high private returnability for the learners. The net private returnability from higher education in the course of the entire professional career in the OECD countries average is 258440 dollars for the males, which is almost twice more than the net private returnability from secondary education, which for the males is 112400 dollars. Although females with higher education are more, the net private returnability from higher education with them is lower - 167600 dollars. Males have also higher inside rate of returnability of educational investments $-12 \%$ for secondary and $14 \%$ for higher education, against only $12 \%$ and $8 \%$ respectively with the females.

Education ensures high returnability also for the public funds invested in it. As far as the ones, who studied more, get higher and safer income, they pay higher taxes. About $40 \%$ of the income generated by education in the OECD countries turns into public income in the form of tax and social insurance payments. Because of them as well as of less public expenses for the highly educated, the net public returnability in the OECD countries is about 67000 dollars from the secondary and 143000 dollars from the higher education of males. Considering public expenses (direct transfers and missed tax revenues) and benefits (revenues from taxes and insurances, and lower expenses for social aid and unemployment compensations) from the various educational degrees, this means $10 \%$ inside rate of returnability of public expenses for higher and $9 \%$ for secondary education of males. These values with the females are lower $-8 \%$ for higher as well as for secondary education. (OECD, 2016, pp. 136-138).

Education and its social-economic consequences are connected by two-way cause-and-effect connections. On one hand, higher levels of qualification are more and more appreciated and the possibilities for the lowly educated are worsening more and more. Low education causes unemployment and poverty, and the differences in education - inequality and social exclusion. On the other hand, material, cultural and social inequalities limit the chances of young people to acquire the necessary education and skills to cope with life. This is realized through two channels. First, it is the direct access to education. Individuals in unequal position suffer hunger and illnesses, are engaged in conflicts, live remotely and do not have convenient transport to schools. This makes education impossible, even if it is desired. Marks show that globally, almost 264,3 million people do not have access to education. 61 of them or $23 \%$ are children aged from 6 to 11 years, 62 million, 23\% are aged 12 to 14 years, and 141 million, $53 \%$ are between 15 and 17 years. (UNESCO, 2017) Second, for those, who anyway get access, social-economic inequality influences the quality of what and how much they can learn. The ones growing in poverty, neglecting family environment and without control are deprived of valuable cultural and social capital. They do not get support from their families, which, even though having the desire to support them, do not occupy the necessary capacity and do not supply them with the necessary cultural tools for constructing appropriate life strategies. (Swidler, 1986) They often have insufficient lingual culture and do not have good command of the official language. It is more likely for them to experience permanent stress from the violence, criminality and poverty they are surrounded by. All that holds back the development of cognitive abilities of schoolchildren and students from poor families and reduces their educational achievements.

Breaking such a vicious circle is beyond the power of free markets because of the presence of market failures, caused by the presence of outside effects, the asymmetric information about the individual capabilities, the failure of financial sector in ensuring crediting, the limited mobility. Personal interest in good 
perspectives for employment and in the high returnability from education is not enough for ensuring satisfying quantity and quality of education. People invest in it less that the optimum because of market failures.

This imposes measures that neutralize market failures and thus, first, guarantee equal access to quality education in educational environment, despite of social status, ethnicity and specific needs, and, second, support the educational achievements of young people from vulnerable groups. There is theoretical and political consensus on these issues, significant funds are allotted and many policies are applied. Subsidizing the education to the full amount of the positive outside effects of it, ensuring additional opportunities for public and private funding of education, improvement of information structure of educational market through development of mechanisms for accrediting and the rating systems, supporting the possibilities for mobility are among these. Such measures would eliminate social injustices and would give equal chances and opportunity for all to invest in their own human capital.

This would be enough for human capital accumulating and for guaranteeing social progress and perspectives for better life for all in an ideal world, where people are rational and consider future consequences of their nowadays actions.

World is not ideal though. Even if young people and their families be ensured equal opportunities to invest in education and to get better life, even if this is the best life alternative for them, they would hardly take completely advantage of these opportunities. This is irrational but people often take decisions and follow behaviour that deviate from the principles of rationality and is not in their interest.

The reasons for not realizing accessible and advantageous investments from personal interest point of view investments in human capital are numerous and lay in behavioural reactions. The present work would be limited on only some of them. Number of modern publications in the field of behavioural economy offer more detailed analysis (Lavecchia, Liu, \& Oreopoulos, 2015).

\section{LACK OF FORESIGHT AND HYPERBOLIC DISCOUNTING}

A child does not attend school because, in search of better life, it wants to invest in its human capital. It makes it if it is fun for him and if there is not anything it considers better for the moment. Student is not far more different. He also lives for today and is mainly driven by his perceptions of what he gets at the moment, not by rational considerations about the future consequences of his present decisions regarding education. We mature with age but irrationality does not disappear. Most of us continue being focused too much on the present day and cannot evaluate well neither their perspectives' usefulness, nor their probability.

The most often reason for the rather high estimation of the today benefits and expenses and the rather low estimation for the future ones, lays in the fact that the usefulness received in short-term future has been discounted with higher rate than the benefit in longer-term future. This makes individuals more impatient for the decisions that regard the present week rather than the following years. Richard Thaler carries out an inquiry, where he asks the respondents what a sum of money they would like to have in 1 month, 1 year and in 10 years in order to be indifferent in receiving 15 dollars now. The average answers -20 dollars, 50 dollars, 100 dollars - mean that the average yearly rate of discounting is $245 \%$ at one-month time horizon, $120 \%$ at one-year horizon and only $19 \%$ at 10 -year horizon. (Thaler, 1981) The technical term for such a time decreasing and giving bigger relative weight to consumption in earlier periods rate of discounting is „hyperbolic discounting“. (Ainslie, 1975, pp. 463-496; Kirby, 1997, p.54-70; Laibson, 1997, pp. 443-477)

Hyperbolic discounting changes the attitude towards distant future and creates 'lack of foresight' and 'present-biased preference': at the choice between two future moments, the weight of the preceding one increases, when it becomes closer. When consequences are in the distant future, people make plans that look far away. However, when distant future becomes immediate and actions become necessary, then their decisions and actions often suffer lack of foresight and inconsistency compared to previously made plans.

The lack of foresight in decision-making covers all fields. It is the reason for many people to consume goods that later cause negative dependencies and lead to serious personal, family and social damages (too much food, alcohol, cigarettes, drug substances, gambling), avoid beneficial choices that require short-term denials and bring benefits in long time-term (such as healthy lifestyle, sport), to delay urgent tasks (such as up-date of the used software) or to spend too much time for tasks that should be postponed (for example, e-mail check), to prefer directing their financial resources to achieving current goals and to invest far less in innovative ideas and business projects with future returnability as well as in their own health and retirement insuring.

Regarding the field of education, because of the same lack of foresight, the present efforts and expenses education requires are clearly seen, but the future benefits of it are strongly underestimated. Writing 
homework, being attentive and participating in class, studying for examinations, focusing on the harder subjects that ensure entering perspective specialties, exploring universities' tuition offers and opportunities for tuition funding requires substantial efforts at present as well as giving up tempting alternatives. Games, television, meetings with friends seem far more attractive. Compared to the latter, the future benefits of education look small, unsecure and distant. Such a lack of foresight leads to negligence of educational opportunities and when the future turns into reality, the regret for the missed opportunities comes. The level of impact depends on such factors as stress, absent-mindedness because of other issues and cognitive development, which means that the groups in unequal social-economic position would suffer much more from lack of foresight.

Lack of foresight regarding education decisions is surmountable. Various techniques for goals and end results visualisation, acquiring clear notion about future, patience and appropriate orientation towards choices time aspects have good effect. (Becker, Mulligan, 1997, pp. 729-758) As far as only emotionally presented goals work, in order to change the orientation towards the future, focusing on long-term goals should use imagination and emotions. Many business ideas successfully exploit these recommendations and achieve success in encouraging savings and investments. The participants in four separate Stanford University studies are asked to review computer graphics of their faces in the future. The conclusion is that the ones, who see their supposed virtual future, show increased bias towards giving priority rather to future than to immediate benefits. (Hershfield, 2011, pp. s23-s37) Taking advantage of these conclusions, Bank of America Merrill Edge develops an application that allows users to visualize how they would look like in some time. ${ }^{1}$ The application changes the present picture with forecasted one for the time of coming of age for retirement, showing at the same time notice about the supposed increase of life expense and advertises the bank's retirement tools. The effect of future visualization is significant. The estimation is that the platform use increases the number of people, who start thinking for participating in a retirement plan, by $60 \%$. It also makes them allocate more funds for ensuring their future. Today more and more institutions consider the inclusion of similar elements of playing in their applications, including interactive functions that offer virtual tour in the future. This is how people are able to visualize themselves in various stages of life and to review their forecast income and status in each important moment of their life cycle. Using similar technology, educational institutions are able to present to them an optimistic picture, where they are secured and wealthy and then to show them what, how much and how to study in order to turn the optimistic picture into reality. They can also stake on avoiding losses, suggesting them a negative picture and following advice how to avoid it by studying. Such strategies could potentially run over or soften the deviation to present and thus to convince more young people to study.

The appropriate understanding of future and rendering knowledge that root the naive notions that people are able to control themselves and that their future preferences would be identical with the present ones, could be supplemented with other measures, too. For example, ones that prevent individuals from wrong actions by preliminary binding of their own behaviour. (Prelec, 2004, pp. 511-532; Thaler, Shefrin, 1981, pp. 358361; Wertenbroch, 1998, pp. 317-337) When outside awards are late, the increasing of immediate benefits from the educational choices also changes behaviour in the desired direction. Awards for small current achievements stimulate the desired immediate behaviour as well as the achieving of the long-term result. Even systematic control of preparation in its body and the feedback about the progress toward the goal could create a positive motivation.

\section{BIAS IN FAVOUR OF THE STATUS QUO}

Very often, individuals have bias in favour of the status quo and give way to momentum even if they are in front of new and better alternatives. The status quo bias gains its name in 1988 in an article by William Samuelson and Richard Zeckhauser (Samuelson, Zeckhauser, 1988, pp. 7-59). There, through series of observations, they demonstrate people's striving to avoid something new even if it promises them a lot of benefits, and the expenses connected to dropping off the old one are low. They vote for the acting politicians, even if they had disappointed them; prefer laws not to be changed often, even if they are aware of the need of reforms; buy from the same stores and buy the same products, although they are bored with them; stick to friendships and relations, which, they are aware, are damaging to them. More, the status quo bias is stronger manifested, when the alternatives to it are more. (Samuelson \& Zeckhauser, 1988, pp. 7-59) Because of an identical reason, half of the university professors in Harvard have never made changes in their retirement plans, even when new and better offers emerge. At the same time, the ones that enter later rarely choose some of the old plans. Such behaviour is inexplicable from the standard theory of choice, as far as there is no reason for the old and the new lecturers to have different preferences. However, it could be easily explained with the status quo bias.

\footnotetext{
${ }^{1}$ Face Retirement ${ }^{\circledR}$, Bank of America, https://vimeo.com/78214928
} 
Individuals have bias in favour of status quo, because status quo is a natural referent point and this is what makes the loss of the option for its preservation to look greater that the benefit from the alternative options, even if they are objectively better. (Kahneman, Knetsch, Thaler, 1991, pp. 193-206) Becoming addicted to the status quo has strong cognitive and emotional grounds. It overestimates the current state, which decreases the probability for people to change it in a certain way. That is why it is very difficult to avoid it or to help the others get aside from it, when it is not the optimal decision. We will illustrate by the fact that people rarely react to the Internet web sites and mail servers prompts to change their access passwords. On one hand, the choice of a new password is choice among practically unlimited number of options, which makes the decision difficult and leads to behavioral paralysis. On the other hand, people are aware of their limited abilities to memorize and the danger of forgetting their new password. Thus, practically, the password change creates potential danger of losses (for example, of time to restore the forgotten password), and the striving for avoiding losses leads to sticking to the current password or to its slight changing, which, from security point of view, is useless.

David Gal claims that people would have status quo bias, led by two more proved psychological principles. (Gal, 2006, pp. 23-32)

First, they'd prefer it, when they have no clear preference between it and some of its alternative options. Although, according to the traditional theory of choice, the individual in such cases should be indifferent between the status quo and these alternatives, in the conditions of an actual choice he would prefer to stick to the known option, which is the status quo, instead of its vague alternatives. The effect in this case is product of the so called ambiguity aversion.

Second reason is the aptitude for experiencing stronger pity for our actions, rather than for our inaction. The aptitude for blaming more strongly harmful action than inaction, is also popular as omission bias. We'd illustrate it through the following reasoning experiment: Imagine that you are married and have an year old child. Would you vaccinate it if: there is $10 / 10000$ probability your child to die of flu without vaccination and there is 5 / 10000 probability the vaccine itself to cause death? Rationality requires the vaccine to be preferred, but led by the reluctance the tragic result to be provoked by own active action, most of the respondents answer with „No“. (Ritov, Baron, 1990, pp.263-277) The insufficient estimation of inaction often manifests at times of investment decisions, too. Imagine for example that Mister $\mathrm{X}$ has bought shares to the amount of 30000 leva years ago and forgot about them. When he founds them and checks their value, it turns it has not changed in the course of years and he decides to keep them. However, few months later, shares surprisingly drop and lose their value totally. As a result, Mr. X realizes he has lost 30000 leva. His acquaintance, Mr. Y also possesses forgotten shares to the amount of 30000 leva but in another company. When he remembers about them and finds they have preserved their value, he decides to sell them. Few months later, the sold shares double their value. Mr. Y realizes he has 30000 leva less than he could have if he hadn't sold his shares. Both men start from the same position, both come to the same state (possess 30000 leva less than they could have). However, the two of them are hardly pleased with their decisions the same way. Mr. Y would regret more perhaps, because of the distortion due to the insufficient estimation of inaction.

In most cases regarding education decisions, there is no problem when relying on habit and following previous behaviour. Problems arise, when the old habits have to exchange with new ones. The transition from school to university is a typical example that requires habits change and much personal responsibility at the decision making of whether to attend he lectures, whether and which book to study after, what optional and extra subject to be chosen, how much time to be spent for additional preparation, etc. The inability of many secondary schools alumni to do this change prevents them from being admitted in a good higher school or makes them fail yet at the first semester examinations.

The solution in such cases is the educational institutions to invest time and care in building up new good habits. This requires a lot of conscious efforts: continuous reminding, contact with and involvement of families, tutorship, monitoring and advising, but once the habit is built up, then no conscious effort is necessary for the routine activities and results come shortly after.

\section{STEREOTYPES AND CONSERVATISM}

When taking decisions about education, people stick not only to their habits but also to their stereotypes and previous information. They rarely look for new information and options. In case an individual has acquired or established certain opinion, it is very difficult to change it and becomes grounds for forming superstitions, for loading with expectations for the members of a particular group and for stereotypical reactions.

Individuals themselves also act differently and achieve different results, while their socio-cultural identity, object of stereotypes, activates. Proofs of the latter are given by an intriguing experiment with girls of Asian 
origin, which verifies how stereotypes connected to sex and origin influence academic achievements (Shih, Pittinsky, Ambady, 1999, pp. 80-83). Within the experiment, by few introducing questions before a Math test, a randomly chosen group of participant has been reminded they are girl and another one that they are of Asian origin. The goal is to find what an effect on achievements the activation of the negative cultural stereotype that girls manage worse in Mathematics as well as the positive stereotype that Asians do well in Mathematics would have. The results are that the participants that are reminded they are girls perform far worse that the ones reminded they are of Asian origin. The experiment has been repeated with an English language test. The stereotypic expectation (girls are good, and Asians are not good in English language) influence the performance here, too. The participant, who have been reminded their sex, manage better with the English language test than the ones reminded their Asian origin. This study conclusion is that stereotypes activation influences the behaviour and achievements of people, who have been object of stereotype notions.

Stereotype influence's direction is not single. Behaviour and achievements might worsen and people might become victims of their own stereotypes if negative notions activate. It is this way, when girls are reminded of their sex before a Math test or of their Asian origin before an English test. Stereotype strengthens girls' anxiety and fear of the test, which prevents them from manifesting their knowledge; diverts their attention from the test itself, which increases the probability them to miss substantial information; makes them give up looking for solution sooner, because they attribute their difficulties with harder problems to their own deficiencies, not to the problems' complexity. (Чалдини, 2016, стр. 210) Performance anyway could improve if positive stereotypes activate. They enhance initial confidence the way, when girls are reminded of their sex before an English test or of their Asian origin before a Math test. Because of that, in order to stimulate a certain group's achievements, the emphasis is to be put on its identity's aspects that trigger positive stereotypes as well as the mechanisms triggering negative notions to be suppressed.

Corroboration is given by an experiment that studies the connection between stereotype expectations about different sexes' intellect and the performance in Mathematics. (Davies, Spencer, Quinn, Gerhardstein, 2002, pp. 615-628) There, two groups solve an identical Math test. The first group is informed the test studies the intellectual capabilities. The boys in this group manage far better than the girls. The second group gets the instruction the test does not deal with the intellectual capabilities but aims psychological processes study. This eliminates the stereotypic expectations' impact about the performance concerning the sex and, as a result, girls perform completely equivalently. Such a result means differences in intelligence and capabilities of both sexes are not genetically predetermined, are not fixed and cannot be identified by testing. Society's socio-cultural stereotypes have much bigger influence on their emergence.

Similar to stereotypes, sticking to previous information may also occur being strong and much damaging. The cognitive deformation that explains the phenomenon is known as "conservatism". Its essence is that people react insufficiently to new information in unknown and complicated situation and stick to a considerable extent to initial information, views and forecasts. (Barberis, Thaler, 2003, pp. 1053-1128) Sticking to previous views may have a more powerful form, when the brain depreciates or completely ignores facts that do not correspond to the views, and perceives only those that confirms them. This illustrates another cognitive deformation called "confirmation bias" - priority is given to the information that confirms current beliefs and the information contradicting them is filtered, ignored, automatically rejected or incorrectly interpreted. (Barberis, Thaler, 2003, pp,1053-1128; Шърмър, 2010, 99-102) The result is that, on one hand, there are too strong reactions to the news confirming the initial positions, and the reactions towards those that does not support them are too weak. This strengthens the confidence in the own positions and actions and generates overpious self-confidence.

Proofs whether existing views are true or not should be continuously looked for in the new facts. And if they are not true, they should be changed. The more a thing is believed, the more facts supporting it are overestimated, and the more facts rejecting it are underestimated. There are two reasons for that. First, less cognitive efforts are required for processing information that supports than for information that contradicts the views. All information that confirms beliefs is perceived with cognitive ease and is accepted. Sticking to it, people avoid greater cognitive effort that accompanies views change. Second, the encounter of proofs that contradict the own views and disturb the reality map, is threat for the ego, which is reacted the way each other threat is reacted to - either with "confrontation“, or by "escape“. That's why, even coming across such proofs, many people address them with skepticism, filter them or adapt their attitude they way they keep the sense of the solutions and positions they had in the past, have been correct. Acknowledging and confronting past mistakes is harder than rationalizing them and sticking to them.

Because of all that, when parents choose primary and secondary school for their children, many choose the closest one, not the most appropriate for them. (Hastings, Weinstein, 2008, pp. 1373-1414) Some studies (Hoxby, Avery, 2013) prove that skillful university students from families of low income choose their known 
and slightly selective higher school before the more selective unknown higher school, which does not require higher expenditures. They more often than the others become victims to the publications about increasing educational expenditures, double overestimate educational expenditures and seriously underestimate its returnability. Moreover, this is in a situation, where information is public and freely accessible via Internet. Obviously, necessary information being available is not enough.

Practice shows that sending information directly to the potential applicant in the form of information package increases considerably the number of applicants in the more selective higher schools. (Lavecchia, Liu, Oreopoulos, 2015) Thus, not only better information is ensured but an impact is also realized through anchoring, priming, looking for reciprocity and preliminary binding.

Of course, the rendered information on the educational opportunities and the perspectives they open should be carefully selected, simplified and systematized. The lack of information does not allow for taking a good decision but the same effect has the rather abundant information, too. Ensuring information does not mean it would be read; reading it does not mean it would be understood and used at the decision-making; the increasing volume and complexity of information increase the probability of it being completely ignored. If too much information is revealed, it would even have negative effect. (Loewenstein, Sunstein, Golman, 2014, pp. 391-419) A lot of people would refuse to make themselves familiar to it or would not pay the necessary attention as it is with brochures accompanying medicines; others would not be able to understand it as it happens most often with contracts in the field of finance; and others would not be able to interpret it correctly, would get confused in their estimations and comparisons, and would also ignore it. There is not much use of ensuring the information in this situation.

\section{PARADOX OF CHOICE}

We should be aware that if most of the simplified and systematized information would improve educational decisions, then most opportunities for choice would be with negative effect.

Traditional theory of economics states that much individual freedom is necessary in order to maximize personal and social well-being. The reasons are at least three: first, freedom itself is a value and grounds of us being humans; second, if we have freedom, we'd be able make the choices that maximize our own wellbeing ourselves and nobody would decide for us; and third, if we have more options to choose among, it is more probable to find the one that suits best our personal preferences and limitations. The way to enhance freedom is to extend choice. The greater choice people have the greater freedom they have. Moreover, the more freedom they have, the greater their well-being is. If a particular possibility for choice does not suit them, it could just be ignored. In addition, limiting the possibilities means more of the rest smaller possibilities for choice should be consumed, which triggers the law of diminishing marginal utility and restrict the overall utility that might be gotten from consumption.

Information-educational policies broaden possible choices undoubtedly. Generally, this is useful but when the decision-maker faces a difficult choice, flooded with information, pressed by the lack of time or has no experience in estimating various alternatives' expenditures and benefits, excessive choice is undesired. (Chernev, Böckenholt, Goodman, 2015, pp.333-358) The load of the too many possibilities for choice evokes the desire for postponing the decision taking. (Tversky, Shafir, 1992, pp. 358-361) Decisions are taken very difficultly because of the far too extensive choice, which leads to paralysis and the satisfaction of making choice decreases. (Schwartz, 2004) This phenomenon is known as „paradox of choice“.

The paralysis of too many alternatives is easily understandable if we imagine what a task a family has to choose school for its child by visiting the possible educational institutions making the least expenses (distance, time for travelling): to start from a school, accepted as a starting point, and get back to it without passing the same school two times. If the schools are only 10, the possible routes are 181440 , and if the schools are twenty - the routes increase to 60822550204416000 . Obviously, it is very difficult to study all possible solutions and to choose the optimal out of them: elaborating optimizing algorithm is complicated and it cannot be made; if anyway it is elaborated, the time for its realization increases so quickly that practically, it cannot be used for tasks from the reality. Here, heuristic approaches are much more useful and practically applicable. They are based on experience and routine, which reduces possible alternatives to several, with which a decision closest to the optimum one could be found. However, they lead to mistakes.

The same paralysis is observed in academic circles. At the assignment to write an essay for additional points in the Stanford University, some participants choose from 6 topics and others have choice among 30 topics. The result is that $74 \%$ of the first ones and $60 \%$ from the others submit essays within the given time terms. (lyengar, Lepper, 2000, pp. 995-1006) Great choice troubled the students more than the limited one. A recent study maintains that the abundance of possibilities for choice of subjects, specializations and lecturers increases the number of the dropped out students, particularly when the students' choices are not well 
structured. (Scott-Clayton, 2011)

This problem's solutions lay in the good structuring of ratings, curricula, programmes and choices in the educational system, their limiting within reasonable frames, or offering implicit options, which to direct them in the most useful for trainees and society direction.

\section{PEER EFFECT}

Yet Aristotle pays attention to the fact that person is a social creature. People are interconnected by relations they do not realize completely, and which affect their thoughts, decisions and actions deeply. Beliefs, desires and actions of all are affected by social preferences and interrelations as well as by social environment, where the decisions are taken. We are "group thinking individuals“, which look at the world through personal as well as social point of view; we understand what is in the other's consciousness and often act as if our brains are connected in a net with the other people's brains. (Tomasello, 2014) The thing we do is often dependable on the others through the "peer effect". It is that the probability of us having certain expectations, accepting certain belief or acting in a certain direction increases if these are maintained by a big number of people similar to us regarding their demographic characteristics, features and faiths. The thing the others expect, think and do predetermines our frame and makes us copy and follow them. Local social networks, traditions, the past, religion, culture, ideas and norms are of a particular significance for the impact.

What should be considered is that learners are also caring about to what extent their behaviour corresponds to the behaviour of their social environment and are highly pliable to social pressure and social norms.

Peer effects are supported by many examples from education. A study of more than 2000 randomly chosen roommates in the Dartmouth College concludes that at each unit of increase (decrease) of roommate's marks, the marks of the student increases (decreases) by 0,12 units. This means that if a student has grades 4,0 with roommate with grades 4,0 moves to a roommate with grades 3,0 , then his grades would drop to 3,88 . The study compares also the close circle's impact with the starting grades and personal characteristics. It turns out the close circle's impact is $27 \%$ of the own past achievement's and personal characteristics' impact. (Sacerdote, 2001)

Beside the roommates' influence, the peer effect upon the grades reveals also in a study in the USA Academy of Air force. The activity's organization in the Academy offers the possibility for carrying out a natural experiment. The cadets are randomly distributed in "squadrons" of 120 people. They live, eat, participate in sports competitions as a team and train together. It turns out the squadron's average grades' increase by a unit increases the cadets' individual grades by 0,65 units. It is also found that being part of the squadron with better average athletic skills increases the cadet's physical tests' results, too (uplifts, abdominal presses, pushups and racing). (Carrell, Gilchrist, Fullerton, West, 2007)

If the presence of quality environment helps for academic achievements, the best students' leaving has negative effect upon the rest. A new school for talented students opened in Washington, accepting candidates with standardized tests' results and grades within the best $2 \%$. The results of that for the rest of the schools are that "the leave of $1 \%$ of the students with high results increases the percentage of students within the worst $25 \%$ of results by about $9 \%$ ". "(Dills, 2005, pp. 19-28)

A study of the academic frauds in the three military academies in the USA for the period 1959-2002 looks for answer to the question „Whether the occurrence of new swindler turns some of the rest of the students into swindlers, too". It turns out that one additional swindler creates directly 0,55 up to 0,80 new swindlers. However, there is a "social multiplicator" existing, as far as newly established swindlers also create additional swindlers. Because of it actually, the occurrence of one swindler creates 2,21 up to 4,90 new swindlers. (Carrell, West, Malmstrom, 2008, pp. 173-207)

Scientific achievements also heavily depend on the availability of favourable scientific environment. More than a half of the American Noble Prize winners have studied with Nobelists. The University of Cambridge, Stanford University, Columbia University, University of California, Berkeley, Princeton University, University of Chicago, the Howard Hughes Medical Institute, University of California, Santa Barbara, Massachusetts Institute of Technology, Harvard University rank among the first at creating favourable climate.

In general, people tend to follow the norms and behaviour of others, even when it is in contradiction with the common sense and their personal interest. Here the issue of the values the social circle shares is of primary importance undoubtedly - whether it consists of studious people and excellent students or idlers, who dropped off from the educational system and poor students. Unsuitable social circle may lead to giving up excellent educational opportunities, acquiring culture of low educational standards, distribution of academic fraud and overall failure of educational system. 
That is why one of the shortest ways to ensuring the desired behaviour is supporting the building up of appropriate social circle and norms. In addition, if necessary, erasing learners' previous negative identity and creating a new one, suitable for the educational goals in exchange. Of course, breaking with the social circle and its influence is connected with great emotional and social expenses, but if an individual is ready to pay the price and if he has an alternative social group ready to accept him, it is not impossible. It sounds like an idea from The Bourne Identity but in the army, in the police academies and many weighty universities around the world this is the first step after accepting their new entrants.

\section{CONCLUSION}

Behavioral problems are not exhausted with the lack of foresight, momentum, stereotypes, herd behaviour and paralysis at many options. The limitations of present work do not allow us to get into details as well as to review the effects of all mistakes and deformations. But even those little examples confirm the thesis that ensuring young people and their families with equal access and opportunities is important but not sufficient. They have to be helped to take adequate advantage of these opportunities. Particularly those having low socio-economic status and are affected by behavioral failures to a higher extent. To realize that, the issue how and why people actually act should be studied carefully; what are the consequences of everyone's inherent limited rationality, limited will and limited egoism. This is a possible task, because behavioral deformations and mistakes are natural, might be studied through mutual efforts of economists, psychologists and sociologists, and this makes them foreseeable and surmountable. Behavioral policies that would have been effective in that sense do not require great expenses and most of them are in the hands of the educational institutions. If we don't succeed in that, we would just pour public funds in educational policies without achieving the desired result.

\section{REFERENCE LIST}

Chernev, A., Böckenholt, U., \& Goodman, J. (2015). Choice overload: A conceptual review and metaanalysis. Journal of Consumer Psychology, 25(2).

Tversky, A., \& Shafir, E. (1992). Choice under conflict: The dynamics of deferred decision. Psychological Science, 3(6).

Dills, A. (2005). Does cream-skimming curdle the milk? A study of peer effects. Economics of Education Review, Vol. 24, Issue 1.

Lavecchia, A., Liu, H., \& Oreopoulos, P. (2015). Behavioral Economics of Education: Progress and Possibilities. Bonn: IZA DP No. 8853.

Sacerdote, B. (2001). Peer effects with random assignment: Results for Dartmouth roommades. Quarterly Journal of Economics, 116(2).

Schwartz, B. (2004). The paradox of choice: Why more Is less. Harper Perennial.

Grant, C. (2017). The contribution of education to economic growth. K4D.

Hoxby, C., \& Avery, C. (2013). Low-Income High-Achieving Students Miss Out on Attending Selective Colleges. Brookings Papers on Economic Activity.

Gal, D. (2006). A psychological law of inertia and the illusion of loss aversion. Judgment and Decision Making, 1(1).

Kahneman, D., Knetsch, J., \& Thaler, R. (1991). Anomalies: the endowment effect, loss aversion, and status quo bias. The Journal of Economic Perspectives, 5(1).

Laibson, D. (1997). Golden eggs and hyperbolic discounting. Quarterly Journal of Economics, 112(2).

Prelec, D. (2004). Decreasing impatience: A criterion for non-stationary time preference and "hyperbolic" discounting. The Scandinavian Journal of Economics, 106(3).

Loewenstein, G., Sunstein, C., \& Golman, R. (2014). Disclosure: Psychology changes everything. Annual Review of Economics, 6.

Ainslie, G. (1975). Specious reward: A behavioral theory of impulsiveness and impulse control. 
Psychological Bulletin, 82(4).

Becker, G., \& Mulligan, C. (1997). The endogenous determination of time preference. The Quarterly Journal of Economics, 112 (3).

Hershfield, H., Goldstein, D., Sharpe, W., Fox, J., Yeykelis, L., Carstens, L., \& Bailenson, J. (2011). Increasing saving behavior through age-progressed renderings of the future self. Journal of Marketing Research, 48.

Ritov, I., \& Baron, J. (1990). Reluctance to vaccinate: omission bias and ambiguity. Journal of Behavioral Decision Making, 3.

Hastings, J., \& Weinstein, J. (2008). Information, School Choice, and Academic Achievement: Evidence from Two Experiments. The Quarterly Journal of Economics, 123 (4).

Scott-Clayton, J. (2011). The Shapeless River: Does a Lack of Structure Inhibit Students' Progress at Community Colleges. Community College Research Center: CCRC Working Paper No. 25.

Kirby, K. (1997). Bidding on the future: evidence against normative discounting of delayed rewards. Journal of Experimental Psychology, 126(1).

Wertenbroch, K. (1998). Consumption self-control by rationing purchase quantities of virtue and vice. Marceting Science, 17.

Woessmann, L. (2015). The economic case for education. Education Economics, 24(1).

Shih, M., Pittinsky, T., \& Ambady, N. (1999). Ambady, Stereotype susceptibility: Identity salience and shifts in quantitative performance. Psychological Science, 10(1).

Tomasello, M. (2014). A Natural History of Human Thinkin. Cambridge, MA: Harvard University Press.

Barberis, N., \& Thaler, R. (2003). A Survey of Behavioral Finance. Oт G. C. Stulz, Handbook of the Economics of Finance Elsevier.

Shermer, M. (2010). Market thinking. Sofia: East-West.

Davies, P., Spencer, S., Quinn, D., \& Gerhardstein, R. (2002). Consuming images: How television commercials that elicit stereotype threat can restrain women academically and professionally. Personality and Social Psychology Bulletin, 28(12).

Chaldini, P. (2016). Pre-persuasion. Hidden mechanisms of efficient influence. Sofia: East-West.

Thaler, R. (1981). Some Empirical Evidence on Dynamic Inconsistency. Economic Letters, 8.

Thaler, R., \& Shefrin, H. (1981). An economic theory of self-control. Journal of Political Economy, 89(2).

UNESCO. (2017). Policy paper 32: Reducing global poverty through universal primary and secondary education. UNESCO.

Carrell, S., Gilchrist, R., Fullerton, R., \& West, J. (2007). Peer and leadership effects in academic and athletic performance. Hanover: Carrell: Department of Economics, Dartmouth College.

Carrell, S., West, J., \& Malmstrom, F. (2008). Peer effects in academic cheating. Journal of Human Resources, 43(1).

lyengar, S., \& Lepper , M. (2000). When choice is demotivating: Can one desire too much of a good thing? Journal of Personality and Social Psychology, 79.

Samuelson, W., \& Zeckhauser, R. (1988). Status quo bias in decision making. Journal of Risk and Uncertainty, 1.

OECD. (2016). Education at a Glance 2016: OECD Indicators. OECD Publishing.

World Economic Forum. (2016). Global Competitiveness Report 2015-2016. World Economic Forum. 